\title{
Severe burn injury in europe: a systematic review of the incidence, etiology, morbidity, and mortality
}

Nele Brusselaers ${ }^{1,2,3^{*}}$, Stan Monstrey ${ }^{2,3}$, Dirk Vogelaers ${ }^{1,3}$, Eric Hoste ${ }^{2,4}$, Stijn Blot ${ }^{1,3,5}$

\begin{abstract}
Introduction: Burn injury is a serious pathology, potentially leading to severe morbidity and significant mortality, but it also has a considerable health-economic impact. The aim of this study was to describe the European hospitalized population with severe burn injury, including the incidence, etiology, risk factors, mortality, and causes of death.

Methods: The systematic literature search (1985 to 2009) involved PubMed, the Web of Science, and the search engine Google. The reference lists and the Science Citation Index were used for hand searching (snowballing). Only studies dealing with epidemiologic issues (for example, incidence and outcome) as their major topic, on hospitalized populations with severe burn injury (in secondary and tertiary care) in Europe were included. Language restrictions were set on English, French, and Dutch.
\end{abstract}

Results: The search led to 76 eligible studies, including more than 186,500 patients in total. The annual incidence of severe burns was 0.2 to $2.9 / 10,000$ inhabitants with a decreasing trend in time. Almost $50 \%$ of patients were younger than 16 years, and $\sim 60 \%$ were male patients. Flames, scalds, and contact burns were the most prevalent causes in the total population, but in children, scalds clearly dominated. Mortality was usually between $1.4 \%$ and $18 \%$ and is decreasing in time. Major risk factors for death were older age and a higher total percentage of burned surface area, as well as chronic diseases. (Multi) organ failure and sepsis were the most frequently reported causes of death. The main causes of early death ( $<48$ hours) were burn shock and inhalation injury.

Conclusions: Despite the lack of a large-scale European registration of burn injury, more epidemiologic information is available about the hospitalized population with severe burn injury than is generally presumed. National and international registration systems nevertheless remain necessary to allow better targeting of prevention campaigns and further improvement of cost-effectiveness in total burn care.

\section{Introduction}

Burn injury is a common type of traumatic injury, causing considerable morbidity and mortality. Moreover, burns are also among the most expensive traumatic injuries, because of long hospitalization and rehabilitation, and costly wound and scar treatment $[1,2]$.

Worldwide, an estimated 6 million patients seek medical help for burns annually, but the majority are treated in outpatient clinics [3]. Whether inpatient treatment in

\footnotetext{
* Correspondence: nele.brusselaers@ugent.be

'Department of General Internal Medicine, Infectious Diseases and Psychosomatic Medicine, Ghent University Hospital, De Pintelaan 185, Ghent 9000, Belgium

Full list of author information is available at the end of the article
}

a specialized burn unit is required depends principally on the severity of the burn, the concomitant trauma, and the general condition of the patient [4-7]. In the European Union, transport accidents (21.8\%), accidental falls (19.4\%), and suicide (24.7\%) are the three most common "fatal injuries," with burns reported as "other unintentional fatal injuries," together with poisoning and drowning (34.1\%) [8]. Exact European figures about severe burn injury are still unavailable, and most European countries do not yet have a national registration system of hospitalized patients with severe burn injury [9]. In the United States, burns due to fire and flames (fatal in 6.1\%) and hot objects or substances (fatal in $0.6 \%$ ) represent $2.4 \%$ of all trauma cases in the United 
States (based on hospital admissions and death registers) and are responsible for $1.6 \%$ of the traumatic deaths [10]. Published data vary considerably depending on the source(s) and classification system (ICD codes, W.H.O definitions, and so on) used and can therefore be extremely difficult to compare. The aim of this study was therefore to summarize the available European epidemiologic data, based on scientific studies in international journals, instead of (often inaccurate) nationwide estimates.

\section{Materials and methods}

This systematic literature search aimed to include all studies from 1985 until December 2009 reporting on etiology, incidence, prevalence, and/or outcome of severe burn injuries as the major topic [11], from all European states and territories, an area of more than 800 million inhabitants and 250 specialized burn units (Table 1, Figure 1). "Severe" burn injury has been defined as an acute burn injury in need of specialized care during hospital admission. Because the definition of burn unit may be different nationally and internationally (for example, only high care, ...), and several countries did not have specialized burn units (at the start of our study period), we included all hospitalized burn populations. Therefore, the included populations could also be admitted to surgery and pediatric wards, general intensive care units, and so on. The first selection of the search was performed by one investigator (NB) under supervision of the principal investigators $(\mathrm{SB}, \mathrm{EH})$, who are content experts. Language restrictions were set to English, French, and Dutch. Studies only considering deceased patients with burn injury were excluded. Assessment of eligibility of the remaining articles (after exclusion of the irrelevant articles) was performed after mutual consideration. The PubMed search included automatic and manual search strategies with the following MeSH terms: 'burns,' 'epidemiology,' 'incidence,' 'fatal outcome,' 'mortality,' and 'causality,' which resulted in 1,744 hits, in the selected languages and within the selected study period (about humans). Therefore, morespecific combinations were used (for example, searching by country), also consulting the Web of Science, Google, and hand-searching reference lists and citation reports of the relevant articles.

\section{Data analysis}

The following data were collected: (a) basic study characteristics: author, year of publication, study period, country, retrospectively or prospectively gathered data, number of participating centers; setting (burn unit, surgical department); (b) population characteristics: number of hospitalized patients with burn injury, analyzed subgroups (for example, military personal, immigrants), age group (all
Table 1 States and territories of Europe (as reported by the Population Reference Bureau, used by the United Nations when categorizing geographic subregions)

\begin{tabular}{|c|c|c|c|}
\hline Country & $\begin{array}{l}\text { Population }^{a} \\
\text { (million) }\end{array}$ & $\mathrm{HDI}^{\mathrm{d}}$ & $\begin{array}{l}\text { Capital city or largest } \\
\text { city }\end{array}$ \\
\hline \multicolumn{4}{|l|}{ Eastern Europe } \\
\hline Belarus & 9.7 & 0.826 & Minsk \\
\hline${ }^{\text {b}}$ Bulgaria & 7.6 & 0.840 & Sofia \\
\hline${ }^{\mathrm{b}}$ Czech Republic & 10.5 & 0.903 & Prague \\
\hline bHungary & 10.0 & 0.879 & Budapest \\
\hline Moldova & 4.1 & 0.720 & Chisinau \\
\hline${ }^{\mathrm{b}}$ Poland & 38.1 & 0.880 & Warsaw \\
\hline${ }^{\mathrm{b}}$ Romania & 21.5 & 0.837 & Bucharest \\
\hline Russian Federation & 141.8 & 0.817 & Moscow \\
\hline bSlovakia & 5.4 & 0.880 & Bratislava \\
\hline$\underline{\text { Ukraine }}$ & 46.0 & 0.796 & Kiev \\
\hline \multicolumn{4}{|l|}{ Northern Europe } \\
\hline${ }^{\mathrm{b}}$ Denmark & 5.5 & 0.955 & Copenhagen \\
\hline${ }^{b}$ Estonia & 1.3 & 0.883 & Tallinn \\
\hline${ }^{b}$ Finland & 5.3 & 0.959 & Helsinki \\
\hline 'Iceland & 0.3 & 0.969 & Reykjavik \\
\hline bIreland & 4.5 & 0.965 & Dublin (City) \\
\hline b'atvia & 2.3 & 0.866 & Riga \\
\hline${ }^{b}$ Lithuania & 3.3 & 0.870 & Vilnius \\
\hline${ }^{\mathrm{c}}$ Norway & 4.8 & 0.971 & Oslo \\
\hline${ }^{\mathrm{b}}$ Sweden & 9.3 & 0.963 & Stockholm \\
\hline bUnited Kingdom & 61.8 & 0.947 & London \\
\hline
\end{tabular}

\section{Southern Europe}

Albania

Andorra 3.2

Bosnia and

Herzegovina

Croatia (Hrvatska) 4.4

${ }^{\mathrm{b}}$ Cyprus $\quad 1.1$

${ }^{\mathrm{b}}$ Greece $\quad 11.3$

Vatican City State $\quad 0.001$

bitaly $\quad 60.3$

Macedonia, Rep. of 2.0

${ }^{\mathrm{b}}$ Malta $\quad 0.4$

Montenegro $\quad 0.6$

bPortugal $\quad 10.6$

San Marino $\quad 0.03$

Serbia $\quad 7.3$

blovenia $\quad 2.0$

bspain $\quad 46.9$

Turkey $\quad 74.8$

Western Europe

${ }^{\mathrm{b}}$ Austria

8.4

${ }^{\text {b}}$ Belgium

10.8

${ }^{\mathrm{b}}$ France

62.6

${ }^{\mathrm{b}}$ Germany

82.0

¿Liechtenstein

0.04

bLuxembourg

0.5

Monaco
0.818 Tirana

0.934 Andorra la Vella

0.812 Sarajevo

0.871 Zagreb

0.914 Nicosia (Lefkosia)

0.942 Athens

Vatican City

0.951 Rome, Milan (Metro)

0.817 Skopje

0.902 Valletta

0.834 Podgorica

0.909 Lisbon

San Marino

0.826 Belgrade

0.929 Ljubljana

0.955 Madrid

0.806 Ankara, Istanbul

0.955 Vienna (Wien)

0.953 Brussels

0.961 Paris

0.947 Berlin

0.951 Vaduz

0.960 Luxembourg

Monaco 
Table 1 States and territories of Europe (as reported by the Population Reference Bureau, used by the United Nations when categorizing geographic subregions) (Continued)

\begin{tabular}{llll}
\hline${ }^{\mathrm{b}}$ Netherlands & 16.5 & 0.964 & Amsterdam \\
'Switzerland & 7.8 & 0.960 & Bern, Zürich \\
\hline
\end{tabular}

${ }^{a}$ Population numbers mid 2009; ${ }^{b}$ member states of the European Union (EU); 'member states of European Free Trade Association (EFTA); ${ }^{\mathrm{d}} \mathrm{HDI}$, Human Development Index (2009) [12]: three European microstates are not ranked in the $2009 \mathrm{HDI}$, for being unable or unwilling to provide the necessary data at the time of publication of the HDI ranking (although it could be expected to fall within the 'very high' HDI category). ages, only adult, pediatric or elderly population), exclusion criteria; (c) occurrence rate and outcome (including proportion hospitalized); (d) patient characteristics: mean/ median age and total burned surface area (TBSA), inhalation, gender; (e) etiology: the etiology of the burns was reported in the following five groups: flames/explosion (also including fireworks, and so on), scalds/steam (also including burns caused by warm food and oil), contact burns, chemical burns, and electrical burns.

Because of the various ways of reporting in the different studies, the most common (and numeric) way of

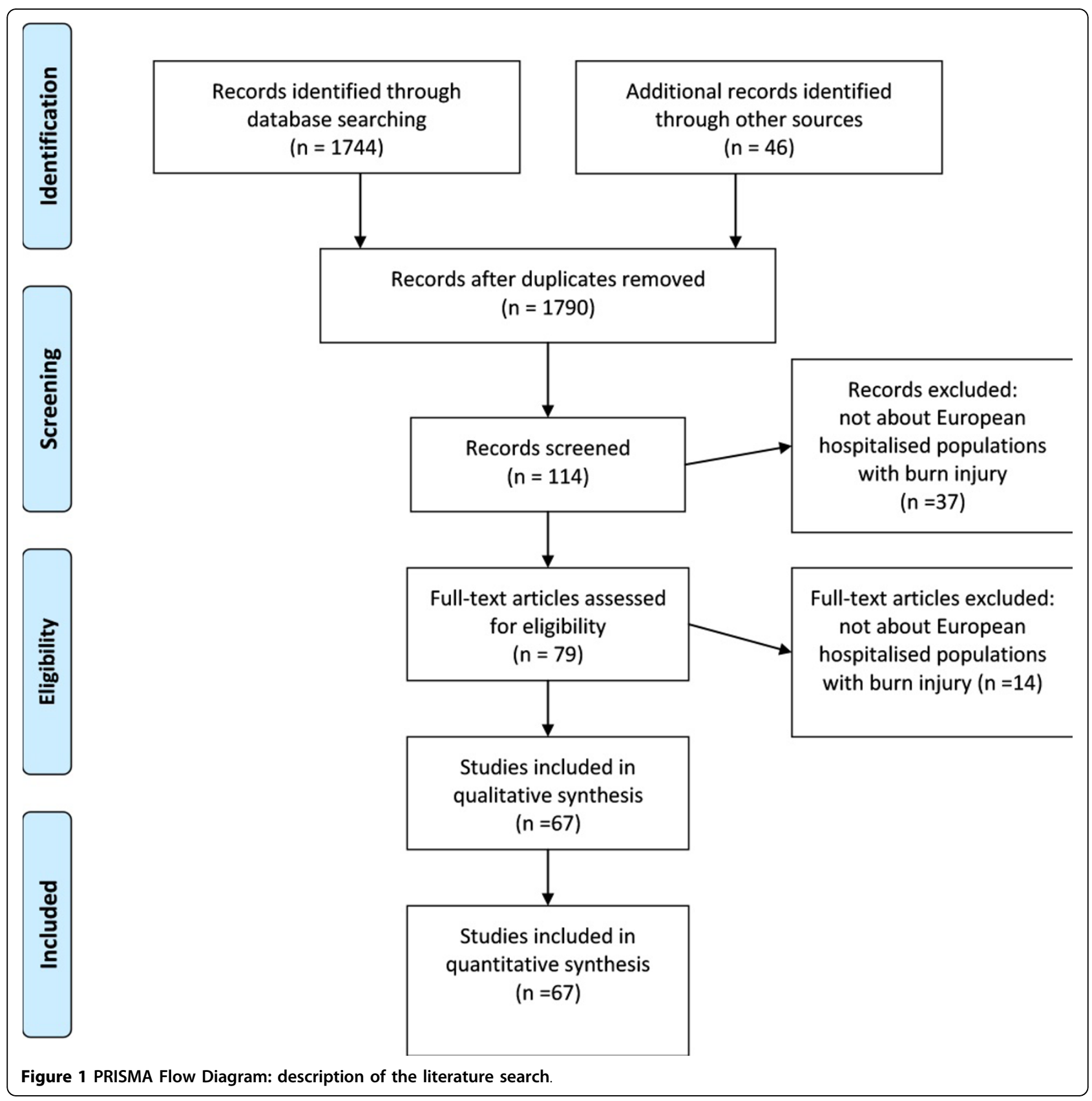


reporting was registered in our database. For certain variables, the most prevalent way of reporting was used for the analyses (for example, mean TBSA instead of median TBSA). For example, if TBSA was only reported graphically (by age group), this could not be used in our analysis. If variables were only reported separately for survivors and nonsurvivors, these variables were not used in the analyses, although they are reported in the main table (cf. Additional file 1). In case of different subgroups, the most 'normal' subgroup was used for the analyses (for example, if a subgroup of immigrants/military personnel was compared with 'native' civilians, only the latter were used in the analysis).

Because mean age and TBSA were provided in several studies, the correlation with mortality could be calculated with a one-tailed Pearson test, and correlation plots were made. A positive correlation reflected in a dependent variable (mortality) will increase if the independent variable (age, TBSA) increases. Box-plots were used to analyze and visualize the proportion of the different etiologies. Statistical analyses were performed with the software program SPSS for Windows, version 16 (SPSS Inc., Somers, NY).

A better standard of life and economy is expected to be related to better health care, which might consequently be related to differences in incidence, etiology, and outcome. Therefore, the studies were also grouped and classified by their Human Development Index (HDI) ranking of the countries [12]. The HDI measures development by combining indicators of life expectancy, educational attainment, and income into a composite HDI. The HDI is in fact a single statistic that serves as a frame of reference for both social and economic development [12]. The HDI sets a minimum and a maximum for each dimension, called goalposts, and then shows where each country stands in relation to these goalposts, expressed as a value between 0 and 1 . All countries worldwide are categorized in four groups by their HDI: 'low' (<0.500), 'medium' (0.500-0.799), 'high' (0.800$0.899)$, and 'very high (0.900 and 1.000) [12].

\section{Results}

We found 76 studies from 22 countries, of which 73 studies were published in English, and three studies, in French [13-15]. For the other European countries, no eligible studies were found. These studies include more than 186.500 patients in total (the total number of patients was not always reported) $[1,13,14,16-58]$. Of these studies, 20 studies considered only children (16 years or younger) [59-78], and 11, only patients of 60 to 75 years or older (described as 'elderly') [15,79-88] populations with severe burn injury (Table 2). The other 45 studies were analyzed together (and described as
Table 2 Number of included studies for each country

\begin{tabular}{llll}
\hline Region & Country & Number of studies & HDI (rank) \\
\hline Eastern Europe & Czech Republic & 6 & $.903(36)^{\mathrm{b}}$ \\
& Hungary & 1 & $.879(43)^{\mathrm{a}}$ \\
& Romania & 1 & $.837(63)^{\mathrm{a}}$ \\
& Slovakia & 2 & $.880(42)^{\mathrm{a}}$ \\
Northern Europe & Denmark & 4 & $.955(16)^{\mathrm{b}}$ \\
& Finland & 4 & $.959(12)^{\mathrm{b}}$ \\
& Iceland & 1 & $.969(3)^{\mathrm{b}}$ \\
& Ireland & 2 & $.965(5)^{\mathrm{b}}$ \\
& Lithuania & 1 & $.870(46)^{\mathrm{a}}$ \\
& Norway & 2 & $.971(1)^{\mathrm{b}}$ \\
& United Kingdom & 14 & $.947(21)^{\mathrm{b}}$ \\
& Sweden & 1 & $.963(7)^{\mathrm{b}}$ \\
Southern Europe & Greece & 1 & $.942(25)^{\mathrm{b}}$ \\
& Italy & 2 & $.951(18)^{\mathrm{b}}$ \\
& Portugal & 1 & $.909(34)^{\mathrm{b}}$ \\
& Spain & 12 & $.955(15)^{\mathrm{b}}$ \\
& Turkey & 3 & $.806(79)^{\mathrm{a}}$ \\
Total & Austria & 3 & $.955(14)^{\mathrm{b}}$ \\
& Belgium & 2 & $.953(17)^{\mathrm{b}}$ \\
& France & 7 & $.961(8)^{\mathrm{b}}$ \\
& Germany & 2 & $.947(22)^{\mathrm{b}}$ \\
& The Netherlands & 4 & $.964(6)^{\mathrm{b}}$ \\
\hline
\end{tabular}

The Human Development Index (HDI) Ranking is a classification of all countries worldwide based on life expectancy, literacy, education, and standards of living. Higher numbers are related to a higher development index (*a 'high' HDI, **b 'very high' HDI).

'overall'). Additional file 1 gives an overview of the most important epidemiologic data available for each study.

\section{Occurrence rate}

Of all patients presenting in the emergency department with burns, between $4 \%$ and $22 \%$ were hospitalized in (intensive care) burn units $[2,19-21,24,27,28]$. The annual incidence of patients with severe burn injury was reported in 22 studies and lies between 0.2 and 2.9/ 10,000 inhabitants. In one Lithuanian study, the incidence was remarkably higher (6.6 in 1991, which decreased to 4.0 in 2004) [57]. It was higher among children, even up to $8.3 / 10,000$ for children younger than 5 years in one Norwegian study [56], and 8.5/10,000 for all children younger than 15 years in a Czech study [75]. A higher incidence has been associated with a lower standard of life and ethnic minorities $[61,62,65]$.

The incidence has decreased over the last 30 years. This was usually reported as the annual number of admitted patients (without denominator), or only graphically. This decreasing trend is (almost) linear, but the decline became less steep since the early 1990s $[24,40,50]$. In Slovakia, a $20 \%$ reduction of the number 
of patients was reported between 1990 and 2004 [22]. The decrease was reported to be present in all age groups [85], but in one Danish study (1987), it was almost exclusively due to a reduction of burns in children younger than 5 years [16]. Another Danish study (1986) reported that the decline is mainly due to a decrease in number of accidents at work [26]. Only two (Icelandic and Czech) studies reported an increasing incidence of pediatric burns $[59,75]$, which was, in Iceland, associated with the increased domestic use of geothermal water $\left(\geq 70^{\circ} \mathrm{C}\right)[59]$.

\section{Age and gender distribution}

Children account for almost half of the population with severe burn injury $(40 \%$ to $50 \%)$ $[14,16,25,34,41,44,58,63,65]$. In one study from Turkey, only $25 \%$ were adults [30]. Children younger than 5 years account for $50 \%$ to $80 \%$ of all childhood burns $[14,32,41,50,64,72,74,78]$. The growth of the elderly population in the Western world is also reflected in the hospitalized population with severe burn injury, by an increasing mean age, or by an increased proportion of elderly ( $10 \%$ to $16 \%$ of the total population with severe burn injury) $[14,33,41,50,58,79-81,83-87,89]$.

In most studies, an overall male predominance of $55 \%$ to $75 \%$ was described. This may be explained by the fact that burn injuries in adults are often work related [2]. In one Austrian and one Turkish study, only one third were men, but this dissimilarity was not discussed or explained in these articles. In the pediatric populations, $60 \%$ to $65 \%$ are boys, but in the elderly population, a female predominance of up to $65 \%$ was found, which might be related to the higher life expectancy in the female gender.

\section{Etiology and circumstances of the accident}

Flames, scalds (including steam), and contact burns were the top three causes of severe burns in most studies (Figure 2). In four studies (from Finland, Spain, Turkey, and Slovakia), scalds were more prevalent than flames (up to $63 \%$ ) $[28,30,41,58]$. In pediatric populations, scalds clearly dominate, accounting for $60 \%$ to $75 \%$ of all hospitalized burn patients, followed by flame and contact burns. Especially children younger than 2 years are at high risk for scalds, and the proportion of scalds is reported to be increasing over the years among pediatric populations $[59,67,68,71]$. In children presenting in the emergency department, scalds were most common (35\% to $80 \%)$, followed by contact burns (13\% to $47 \%$ ), and flame burns (2\% to 5\%) [61-63,72]. In adult patients consulting the emergency department with burns, scalds were more prevalent than flame burns,

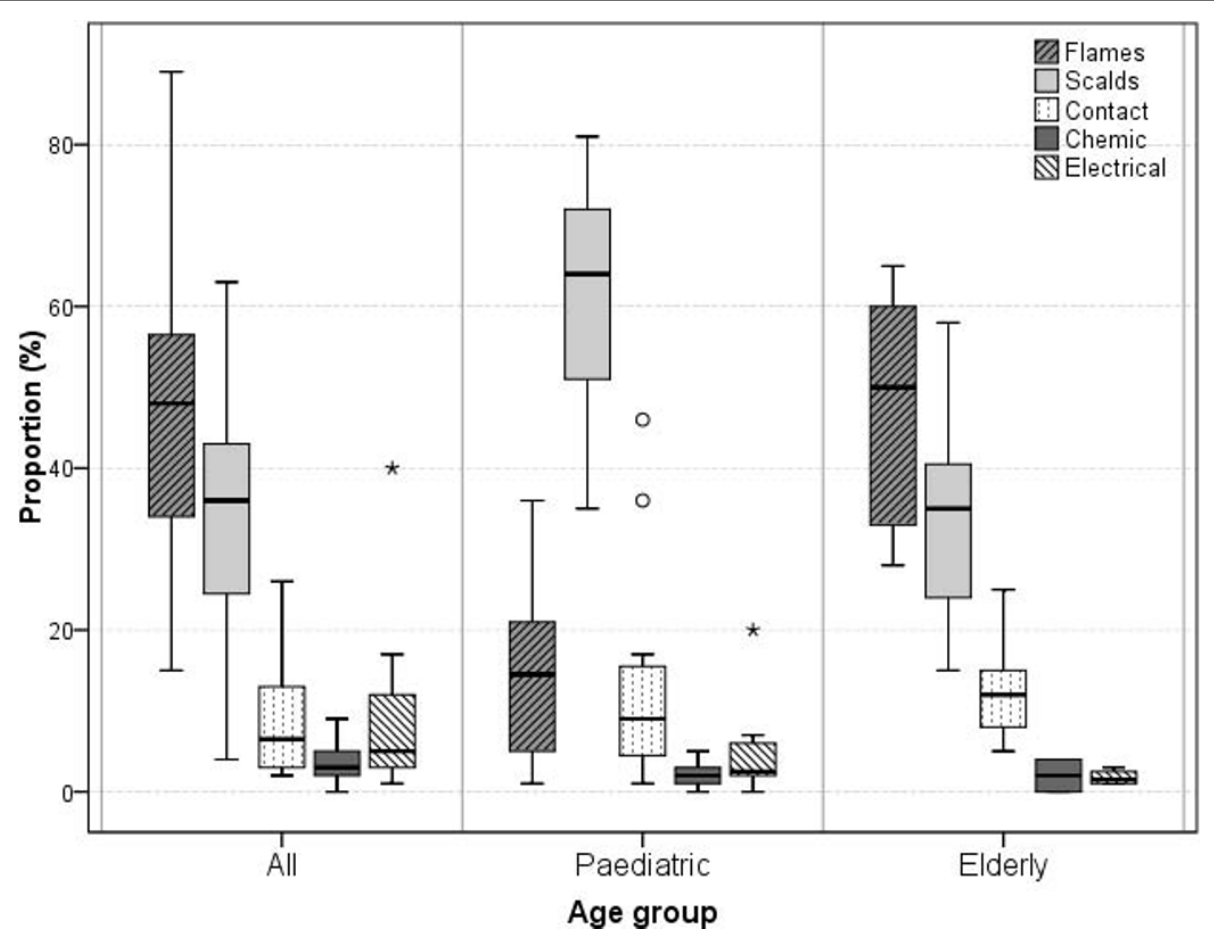

Figure 2 Etiology of severe burn injury, according to the age group (proportion of all burns). Forty-one studies provided sufficient data to compare the etiologies. In the 'All' group, two of the 19 studies consider only adults. The 'pediatric' box plots are based on 14 studies; the 'elderly' box plots, on eight studies. 
although patients with flame burns are more frequently hospitalized $[20,24,28]$.

Flame burns were more prevalent in men, whereas scalds and contact burns were more frequent in women $[41,80]$. Less frequent than flames, scalds, and contact burns are electrical burns, which were generally more frequent than chemical burns (Figure 2). In one Finnish pediatric study, electrical burns $(20 \%)$ were more prevalent than contact burns (none) [60]. Two Turkish studies reported $17 \%$ to $40 \%$ electrical burns, which is supposed to be related to insufficient precautions and safety measures (as reported by the authors) $[30,32]$. Some specific causes of burns have been described separately in several studies (for example, sunburns (up to $5 \%$ of all burns, especially children)) $[20,34,42,66,67,80]$, sauna (up to $26 \%$ of all burns in Finland) [58,70], and fireworks (up to $9 \%$ of all burns) [20,26,44,49, $59,61,66,72,75]$.

The great majority of the burns are accidental, and especially in children, the majority occurred at home ( $80 \%$ to $90 \%)[2,14,41,42,44,59,66,71,75]$. In the elderly, domestic burns (78\% to $85 \%)$ [79,86,88] were followed by recreational accidents in $7 \%$ to $12 \%[80,83]$. In adults, one third were work related $[2,20,35,41]$. The pediatric burns occurred mainly in the kitchen (75\%), caused by hot food or beverages, with the bathroom as second most common location (mostly by immersion, leading to deeper and more extensive burns) [61,66-68]. Scalds in the elderly usually occurred in the bathroom (by immersion), in contrast to scalds in children, which usually occur in the kitchen $[75,79,80,83,85,86]$.

Europe is considered to have the highest number of suicides in the world (World Health Organisation) [90]. However, only eight studies reported the number of self-inflicted burns: in three French (of which two are in the elderly), one Finnish, and one Spanish study, 3\% to $6 \%$ of all burns were self-inflicted [14,44,58,80,83]. In three other studies (from the U.K., Turkey, and Slovakia), this percentage was less than $2 \%[27,40,41]$.

\section{Length of hospitalization}

The mean length of hospitalization (LOS) in the general population with burn injuries was 7 to 33 days (median, 3 to 18 days) [1,2,19,25,29-32,50,52,56-58] and was reduced by $26 \%$ (1992 through 2007), as reported by one Norwegian study [56]. The average LOS in the pediatric population was 15 to 16 days (median, 10 to 12 days), and in the elderly, mean and median were reported as 18 to 26 days $[61,65,67,73,80-84,88]$.

\section{Mortality and associated risk factors}

In most hospitalized populations with severe burn injuries, the mortality rate lies between $1.4 \%$ and $18 \%$ (maximum, 34\%). Several studies showed that older age, increasing TBSA age, and inhalation injury are the three major risk factors for mortality, although other variables have also been associated with a higher mortality risk $[23,36,37,53]$.

The mean TBSA in patients with severe burn injury was $11 \%$ to $24 \%$ and has decreased over the past decades, as reported in two studies [40,52]. The mean TBSA was higher among the deceased patients $(44 \%$ to $50 \%$ overall; $73 \%$ in a pediatric study and $22 \%$ in an elderly population). In some studies, the average TBSA was remarkably higher (up to $55 \%$ ), probably due to more strict admission criteria (for example, only intensive care patients, or only patients with a TBSA $\geq 30 \%$ ), which was associated with higher mortality rates. The mortality increases considerably above a TBSA of $20 \%$ (Figure 3) $[23,53]$. The Pearson correlation test showed a positive correlation between the mean TBSA and mortality in the adult/overall age group $(r=0.741 ; P<$ 0.001 ), as well as in the studies discussing elderly populations ( $r=0.696 ; P=0.028$; cf. correlation plot, Figure $3 \mathrm{a}, \mathrm{b})$, which clearly suggests a higher mortality when the TBSA (of the population) increases.

Another major risk factor for mortality is increasing age, which correlated noticeably with mortality, with $13 \%$ to $39 \%$ mortality among the cohorts of elderly patients. In contrast, a survival rate of $98 \%$ to $100 \%$ was reported in most pediatric series. When the adult and overall studies were analyzed together, a small positive correlation was found between age and TBSA ( $r=$ 0.195; $P=0.235$ ) (Figure 3c). When the studies of the elderly population were also included in the analyses, a more-prominent correlation was found $(r=0.646 ; P<$ 0.001).

Besides age and TBSA, inhalation injury has repeatedly been associated with increased mortality (eight- to 10-fold higher [91]). Inhalation injury is due to smoke inhalation and is therefore especially prevalent in populations with a high proportion of flame burns $[48,52]$. The occurrence rate of inhalation injury is blurred by problematic diagnosis and hence lack of consensus definition. Some studies included all suspected inhalation injury; others, those confirmed by bronchoscopy or only those requiring mechanical ventilation $[13,36,38,44,48]$. Overall, inhalation injury occurred in $0.3 \%$ to $43 \%$ of all hospitalized patients with severe burn injury, and in 13\% to $18 \%$ of the elderly with severe burn injury. Only two pediatric studies reported inhalation injury, in 3.3\% and $69 \%$, respectively $[60,66]$. No clear relation with mortality can be detected in these data.

Seven studies report a higher female mortality $[17,28,31,32,36,42,53]$, but in seven other studies, no significant difference was found or even an increased male mortality $[22,30,38,44,50,54,57]$. In the elderly population, a significantly higher male mortality has been 

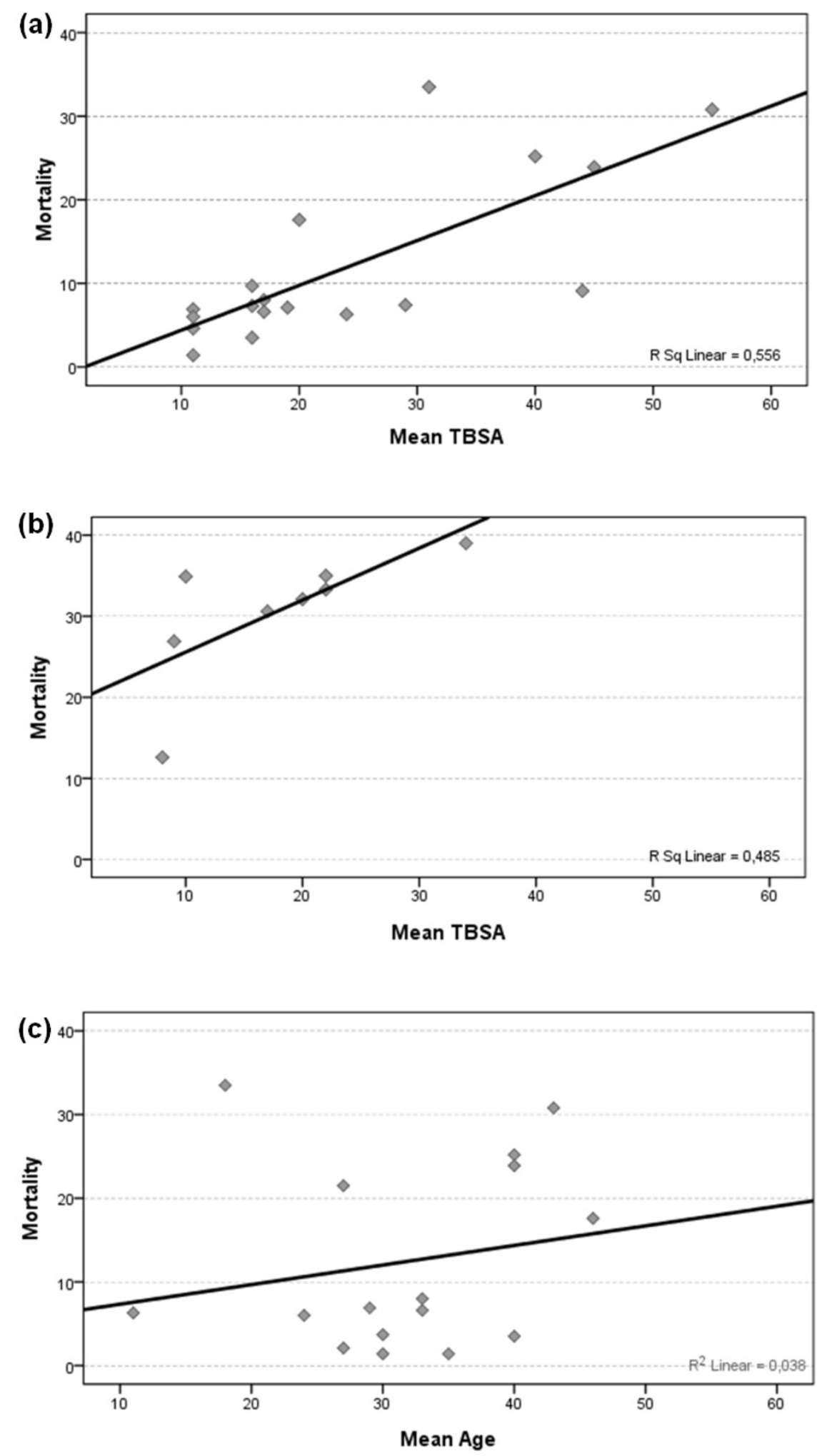

Figure 3 The correlation between risk factors for mortality and mortality. (a) Total and adult populations with severe burn injury: correlation between the mean total burned surface and mortality. (TBSA, total burned surface area). (b) Elderly populations with severe burn injury: correlation between the mean total burned surface and mortality. (c) Total and adult population with severe burn injury: correlation between the mean age and the associated mortality. 
described [44,82]. Risk-adjusted mortality rates considering age and TBSA were, however, not provided, and therefore, no conclusions can be made about the relation between gender and mortality.

Flame burns have been associated with a higher mortality rate, but flame burns have also been associated with more-extended, deeper burns and the presence of inhalation injury $[28,30,32,44,58]$.

Chronic diseases, including lifestyle risk factors such as chronic alcohol abuse and smoking, do compromise the prognosis of the patient with severe burn injury $[36,47]$ and were present in $44 \%$ to $50 \%[79,81,84,86]$. Co-morbidity was especially common among the elderly with severe burn injury (71\% to $85 \%)[15,81,83,84,86]$. Most frequent were cardiovascular (hypertension, ischemic heart diseases) and pulmonary diseases (chronic obstructive pulmonary disease), diabetes mellitus, and neurologic conditions $[15,83,86]$. Chronic alcoholism and psychiatric problems were present in $25 \%$ to $42 \%$ and $13 \%$ to $50 \%$, respectively, of the deceased elderly with severe burn injury $[61,65,67,73]$.

\section{Trends in mortality}

The mortality decreased over the last 30 years (although the reporting of mortality is too heterogeneous to summarize) (Additional file 1). One Spanish study reported, for example, a reduction from $24 \%$ to $12 \%$ mortality, between 1992 and 1995 and 2001 to 2005 [53]; a Turkish study, from $38 \%$ to $30 \%$ (1988 through1992 versus 1993 through 1997) [32]; and a Dutch study reported a decrease from 7\% to 5\% between 1996 and 2006 [51]. A Danish study reported a decrease of mean mortality from four to three annual deaths [16]. The decrease in mortality was more apparent in the male population, as reported by one Swedish study [50], and was also more significant in patient groups of intermediate severity [52].

\section{Cause of death}

Only a few articles report the cause of death, which was usually based not on autopsy results but on clinical pre- sumptions. Early death ( $<48$ hours) was mostly due to burn shock or inhalation injury $[28,42,44,51,86]$. Multiorgan failure was responsible for $25 \%$ to $65 \%$ of all burn deaths $[28,32,42,51,81]$, and sepsis, for $2 \%$ to $14 \%$ $[28,42,84,86]$. Respiratory complications (pneumonia, ARDS, pulmonary embolism) are a major cause of death responsible for up to $34 \%$ among adults $[16,28,42]$, and even up to $45 \%$ among the elderly $[81,84,86]$. Cardiac, renal, and cerebral complications each contribute to less than $5 \%$ of all deaths, but clear trends cannot be described because of the paucity of data. In one Turkish study, $45 \%$ of all deaths were ascribed to acute kidney injury [32].

\section{Socioeconomic status versus burn injury}

Of all 76 studies, the great majority (89.5\%) considered populations with a 'very high' HDI (68 studies). Only eight studies were published in countries with a 'high' HDI, and none, in countries with a medium HDI (Table 2) [12]. The 'very high' HDI countries are overrepresented, because $52 \%$ of the European countries have a 'very high' HDI; 37\%, a 'high' HDI, and 4.3\%, a medium HDI (Table 3).

Mainly because of the lack of studies from the lessdeveloped European countries, and the often incomplete data, it is difficult to compare the impact of economy, standard of living, and so on, on the epidemiologic parameters discussed earlier. Most remarkable are the high prevalence of electrical burns in the three Turkish studies (13\% to $40 \%$ ), especially because only one of the other studies reports a prevalence of electrical burns higher than $8 \%$ (a pediatric study from Finland [60]). The male predominance was also less apparent (or even absent) in the 'high' HDI countries, because three of four studies reporting the lowest proportions of men come from 'high' HDI countries (33\% to 54\%) (studies considering the elderly population were not taken into account) $[27,30,54]$. Insufficient data are available to assess the influence of HDI on other epidemiologic parameters, which is also because of the multifactorial relations between severity, incidence, outcome, and so on.

Table 3 Distribution of studies by Human Development Index (HDI)

\begin{tabular}{llll}
\hline HDI & Number of studies & Number of countries & Number of inhabitants $\left(\times \mathbf{1 0}^{\mathbf{6}}\right)^{\mathbf{a}}$ \\
\hline Very high & $68(89.5 \%)$ & $24(52.2 \%)$ & $423(52.2 \%)$ \\
High & $8(10.5 \%)$ & $17(37.0 \%)$ & $377(41.6 \%)$ \\
Medium & 0 & $2(4.3 \%)$ & $50.1(6.2 \%)$ \\
Low & 0 & 0 & 0 \\
Not known & 0 & $3(6.5 \%)$ & $0.07(0.0)$ \\
\hline Total & 76 & 46 & 810 \\
\hline
\end{tabular}

HDI, Human Development Index. ${ }^{a}$ cf. Table 1. 


\section{Discussion}

This study provides an overview of the epidemiology of severe burn injury in Europe, based on observational studies published in the last 25 years. Despite the lack of a large-scale European registration of burn injury, some strong conclusions can be made. These include a decrease in incidence and mortality, a male predominance, and age-related etiology patterns. The decreasing incidence is almost certainly related to increased awareness of hazardous situations through prevention campaigns and better regulations for electronic equipment. Increased insight into the pathophysiology of burn injury has undoubtedly contributed to improvements in therapy, such as fluid resuscitation, infection prevention, and wound care, leading to a higher survival rate. A decrease in severity of the burns should also be kept in mind, as a decrease in TBSA was noted in two studies. Considering the etiology, flame burns are the most frequent cause among adults, and scalds, among children, but cultural and socioeconomic differences do have a major influence. Although a decreasing incidence of burn injury has been described, the great majority of the burns remain accidental, and therefore are preventable, especially in children. Probably at least as important as further improvements in burn management, prevention of burn injury is crucial to decrease the morbidity, mortality and economic burden caused by severe burn injury [2].

Although this study is based on a cohort of almost 200,000 patients hospitalized with burn injury (which is, as far as we know, the largest ever described), this study has several limitations. Most included studies were small, multicenter studies of retrospectively collected data, but especially the heterogeneity of study populations hampers comparisons. Some differences between studies are probably due to socioeconomic, logistic, or even cultural differences (for example, in cooking and saunas). For instance, the number of burns due to electricity is alarmingly high in Turkey, which is reported to be caused by insufficient information about the dangers of electricity; or even more likely by unsafe electrical appliances and electricity distribution. The variation in the severity of the population with severe burn injury (for example, TBSA) could be explained by differences in the accessibility of the European burn units (differences in the transport network, and geographic distribution and number of the burn units), the admission criteria of the burn units, and/or differences in age distribution or other demographic characteristics.

The differences between the populations with burn injury will also be related to differences in the standard of living and economy. Unfortunately, the quantity and quality of research is often related to the economy and standard of health care, because research is possible only if resources and qualified personnel are available. When compared with studies from other highly industrialized countries in North America, Australia, and Asia, this study provided similar results, whereof the decreasing mortality and incidence, risk factors for mortality, and distribution of etiology are among the most frequent reported parameters [92-95].

It would be interesting to compare the epidemiology of burn injury between highly industrialized countries and developing countries, but national registration is not even established in several highly developed (European) countries, and probably completely absent in several developing countries. For this study, we attempted to analyze the differences between the mostdeveloped European countries and the 'less' developed countries (although the differences considering the human development statistic appeared to be rather small). Because the most developed countries were overrepresented, and thus insufficient data were available, it was not possible to draw strong conclusions considering the standard of living and burn epidemiology. Most remarkable was the absence of a male predominance and higher proportion of electrical burn injury in the least developed European countries. It can be expected that the differences (in standard of living, health care, and so on) between all European countries will diminish even further.

Another limitation of this study is the absence of uniformity resulting in often suboptimal reporting and analyses of data, with other classifications and definitions for etiology, inhalation injury, and so on. For example, the cut-off values for our three age categories (children, adults, and elderly) posed no problem for the pediatric population (younger than 15 to 16 years) but ranged from 60 to 75 years for the elderly.

This study cannot provide a clear answer to the oftenquestioned gender-related differences in outcome, because no risk adjustment is performed in the individual studies to exclude the influence of effect-modifying factors such as TBSA, age, and etiology. The geographic distribution of the available studies also makes extrapolation to the whole of Europe questionable. We aimed at a description of all European countries, but some regions were overrepresented (half of the studies were published in only four different countries), and from certain regions, no data were available at all. This might be due to the language restrictions of our search (we included studies in only English, French, and Dutch), but also due to the predominance of the English language as the international scientific language. The included languages are native languages in only a minority of the European countries (especially located in 
Western Europe), which may hamper publication of studies from non-native English-speaking countries. However, the impact of our language barrier will probably be limited, because the inclusion of French and Dutch contributed to only three additional articles, and $82 \%$ of all studies considered populations in which English was not their native language.

Hence, the further implementation of national and preferably also international registration systems with consensus definitions of hospitalized patients with severe burn injury will facilitate research through more extensive databases and hence will enable detection of possible relations between risk factors. Consequently, a more accurate registration and description of the population with severe burn injury may allow improved targeting of prevention campaigns and cost-effectiveness of total burn care. Therefore, we promote the development of a European-scaled registration network that will provide detailed epidemiologic insights and will allow bench-marking and quality of burn care.

\section{Conclusions}

Although this study is based on a very heterogeneous group of populations from all over Europe, it is based on a very large cohort of patients covering a period of 25 years. Several strong conclusions can be made about age-related etiology patterns and gender distribution, and (trends in) incidence and mortality. National and international registration of burn injuries will enable further epidemiologic research, and will certainly lead to better targeted prevention campaigns and a better, costeconomic multidisciplinary burn treatment.

\section{Key messages}

- Severe burn injuries (requiring hospitalization) still occur often and have a high impact on morbidity and mortality. In some countries, a decreasing incidence is noted over time.

- Half of the patients are younger than 16 years, and up to $75 \%$ of the victims are male patients (except in the elderly population).

- Flame burns and scalds are the most frequent causes of burns among all age groups.

- Mortality varies considerably among different populations (range, $1.4 \%$ to $34 \%$, with a decreasing trend over time), and clearly correlates with an increasing mean total burned surface area.

- National and international registration of epidemiologic data of populations with burn injuries should be promoted. Consensus definitions (for example, inhalation injury) are, however, obligatory to compare different populations and will subsequently improve burn care.

\section{Additional material}

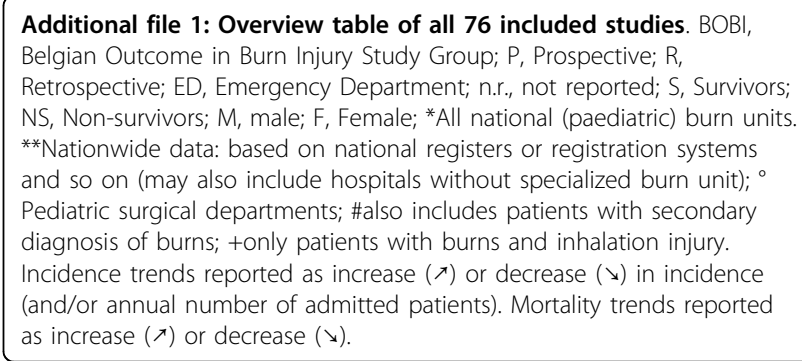

\section{Abbreviations}

LOS: Length of stay (hospitalization); TBSA: total burned surface area.

\section{Author details}

'Department of General Internal Medicine, Infectious Diseases and Psychosomatic Medicine, Ghent University Hospital, De Pintelaan 185, Ghent 9000, Belgium. ²Department of Plastic Surgery and Burn Unit, Ghent University Hospital, De Pintelaan 185, Ghent 9000, Belgium. ${ }^{3}$ Faculty of Medicine and Health Sciences, Ghent University, De Pintelaan 185, Ghent 9000, Belgium. ${ }^{4}$ Intensive Care Unit, Ghent University Hospital, De Pintelaan 185, Ghent 9000, Belgium. ${ }^{5}$ Department of Healthcare, University College Ghent, Keramiekstraat 80, Ghent 9000, Belgium

\section{Authors' contributions}

All authors made substantial contributions to the conception and design. $\mathrm{NB}, \mathrm{EH}$, and SB selected the literature and performed the statistical analyses. The manuscript was drafted by NB, helped by SB and EH, and the manuscript was critically revised by SM and DV. All authors have read and approved the final manuscript.

\section{Competing interests}

The authors declare that they have no competing interests.

Received: 22 February 2010 Revised: 21 April 2010

Accepted: 19 October 2010 Published: 19 October 2010

\section{References}

1. Sanchez JL, Pereperez SB, Bastida JL, Martinez MM: Cost-utility analysis applied to the treatment of burn patients in a specialized center. Arch Surg 2007, 142:50-57, discussion 57.

2. de Roche R, Luscher NJ, Debrunner HU, Fischer R: Epidemiological data and costs of burn injuries in workers in Switzerland: an argument for immediate treatment in burn centres. Burns 1994, 20:58-60.

3. World Burn Foundation. [http://www.burnsurvivorsonline.com/].

4. American Burn Association: Appendix B to hospital resources document: guidelines for service standards and severity classifications in the treatment of burn injury. Bull Am Coll Surg 1984, 69:24-28.

5. Chipp E, Walton J, Gorman D, Moiemen NS: Adherence to referral criteria for burns in the emergency department. Eplasty 2008, 8:e26.

6. Anwar U, Majumder S, Austin O, Phipps AR: Changing pattern of adult burn referrals to a regional burns centre. J Burn Care Res 2007, 28:299-305.

7. Brusselaers N, Lafaire C, Ortiz S, Jacquemin D, Monstrey S: The consensus of the surgical treatment of burn injuries in Belgium. Acta Chir Belg 2008, 108:645-650.

8. Eurostat: Health Statistics: Atlas on Mortality in the European Union Luxembourg 2009.

9. Wedler V, Kunzi W, Burgi U, Meyer VE: Care of burns victims in Europe. Burns 1999, 25:152-157.

10. National Trauma Data Bank: Annual Report version 8.0.Edited by: Nathens $A B$, Fantus RB. The American College of Surgeons Committee on Trauma; 2008: 
11. Moher D, Liberati A, Tetzlaff J, Altman DG: Preferred reporting items for systematic reviews and meta-analyses: the PRISMA statement. PLoS Med 2009, 6:e1000097.

12. United Nations Development Program (UNDP): Human Development Report 2009: overcoming barriers: human mobility and development. United Nations Development Program 2009.

13. Griffe O, Gartner R, Captier G, Brabet M, Baro B, Selloumi D, Otman S: Evaluation of prognostic factors in the burned patient. Ann Chir Plast Esthet 2001, 46:167-172.

14. Perro G, Bourdarias B, Cutillas M, Castède JC, Sanchez R: Analyse epidemiologique de 2000 brulés hospitalises à Bordeaux entre 19871994. Ann Burns Fire Disasters 1996, 9:131-138.

15. Desouches C: Influence des pathologies associees et de l'age sur la mortalité des patients brûlés ages de plus de 65 ans. Brûlures 2000, 1.

16. Elberg JJ, Schroder HA, Glent-Madsen L, Hall KV: Burns: epidemiology and the effect of a prevention programme. Burns Ind Therm Inj 1987, 13:391-393.

17. Barisoni D, Peci S, Governa M, Sanna A, Furlan S: Mortality rate and prognostic indices in 2615 burned patients. Burns 1990, 16:373-376.

18. Anlatici R, Ozerdem OR, Dalay C, Kesiktas E, Acarturk S, Seydaoglu G: A retrospective analysis of 1083 Turkish patients with serious burns. Burns 2002, 28:231-237.

19. Wilkinson E: The epidemiology of burns in secondary care, in a population of 2.6 million people. Burns 1998, 24:139-143.

20. Hove LM, Lindtjorn B: Epidemiology of burns in Bergen, Norway. Scand J Plast Reconstr Surg Hand Surg 1999, 33:225-229.

21. van Rijn OJ, Grol ME, Bouter LM, Mulder S, Kester AD: Incidence of medically treated burns in The Netherlands. Burns 1991, 17:357-362.

22. Babik J, Sopko K, Orsag J, Koller J: Epidemiology and therapeutic aspects of burn injuries in Slovakia (1993-2003). Acta Chir Plast 2006, 48:39-42.

23. The Belgian Outcome in Burn Injury Study Group: Development and validation of a model for prediction of mortality in patients with acute burn injury. Br J Surg 2009, 96:111-117.

24. den Hertog PC, Blankendaal FA, ten Hag SM: Burn injuries in The Netherlands. Accid Anal Prev 2000, 32:355-364

25. Tejerina C, Reig A, Codina J, Safont J, Baena P, Mirabet V: An epidemiological study of burn patients hospitalized in Valencia, Spain, during 1989. Burns 1992, 18:15-18.

26. Lyngdorf $P$, Sorensen $B$, Thomsen $M$ : The total number of burn injuries in a Scandinavian population: a prospective analysis. Burns Ind Therm Inj $1986,12: 567-571$.

27. Turegun M, Sengezer M, Selmanpakoglu N, Celikoz B, Nisanci M: The last 10 years in a burn centre in Ankara, Turkey: an analysis of 5264 cases. Burns 1997, 23:584-590.

28. Barret JP, Gomez P, Solano I, Gonzalez-Dorrego M, Crisol FJ: Epidemiology and mortality of adult burns in Catalonia. Burns 1999, 25:325-329.

29. Andel D, Kamolz LP, Niedermayr M, Hoerauf K, Schramm W, Andel H: Which of the abbreviated burn severity index variables are having impact on the hospital length of stay? J Burn Care Res 2007, 28:163-166.

30. Aldemir M, Kara IH, Girgin S, Guloglu C: Factors affecting mortality and epidemiological data in patients hospitalised with burns in Diyarbakir, Turkey. S Afr J Surg 2005, 43:159-162.

31. da Silva PN, Amarante J, Costa-Ferreira A, Silva A, Reis J: Burn patients in Portugal: analysis of 14,797 cases during 1993-1999. Burns 2003, 29:265-269.

32. Anlatici R, Ozerdem OR, Dalay C, Kesiktas E, Acarturk S, Seydaoglu G: A retrospective analysis of 1083 Turkish patients with serious burns, Part 2 : burn care, survival and mortality. Burns 2002, 28:239-243.

33. Rashid A, Khanna A, Gowar JP, Bull JP: Revised estimates of mortality from burns in the last 20 years at the Birmingham Burns Centre. Burns 2001, 27:723-730.

34. Sarhadi NS, Murray GD, Reid WH: Trends in burn admissions in Scotland during 1970-92. Burns 1995, 21:612-615.

35. Gomez-Cia T, Mallen J, Marquez T, Portela C, Lopez I: Mortality according to age and burned body surface in the Virgen del Rocio University Hospital. Burns 1999, 25:317-323.

36. Germann G, Barthold U, Lefering R, Raff T, Hartmann B: The impact of risk factors and pre-existing conditions on the mortality of burn patients and the precision of predictive admission-scoring systems. Burns 1997, 23:195-203.
37. Coste J, Wasserman D, Venot A: Predicting mortality in adult burned patients: methodological aspects of the construction and validation of a composite ratio scale. J Clin Epidemiol 1996, 49:1125-1131.

38. Raff T, Germann G, Barthold U: Factors influencing the early prediction of outcome from burns. Acta Chir Plast 1996, 38:122-127.

39. Herruzo-Cabrera R, Fernandez-Arjona M, Garcia-Torres V, Martinez-Ratero S, Lenguas-Portero F, Rey-Calero J: Mortality evolution study of burn patients in a critical care burn unit between 1971 and 1991. Burns 1995, 21:106-109.

40. Sarhadi NS, Reid WH, Murray GD, Williamson J: Flame burn admissions and fire fatalities in Scotland with particular reference to the Strathclyde (Glasgow) region, and their prevention. Burns 2001, 27:731-738.

41. Koller J, Orsag M, Ondriasova E, Graffinger I, Bukovcan P: Analysis of 1119 burn injuries treated at the Bratislava Burn Department during a fiveyear period. Acta Chir Plast 1994, 36:67-70.

42. Reig A, Tejerina C, Baena P, Mirabet V: Massive burns: a study of epidemiology and mortality. Burns 1994, 20:51-54.

43. Stavropoulou V, Daskalakis J, loannovich J: A new prognostic burn index. Ann Medit Burns Club 1993, 6:1-7.

44. Benito-Ruiz J, Navarro-Monzonis A, Baena-Montilla P, Mirabet-Ippolito V: An analysis of burn mortality: a report from a Spanish regional burn centre. Burns 1991, 17:201-204.

45. Laing $\mathrm{JH}$, Morgan $\mathrm{BD}$, Sanders $\mathrm{R}$ : Assessment of burn injury in the accident and emergency department: a review of 100 referrals to a regional burns unit. Ann $R$ Coll Surg Engl 1991, 73:329-331.

46. Herruzo-Cabrera R, Gil Miguel A, Torres G, Calero R, Mayer Fournaraki RF: Death probability evaluation in critically burned patients with a multivariant adjustment. Ann Medit Burns Club 1991, 4:8-12.

47. Santos Heredero FX, Garcia Torres V, Herruzo R, Fernandez Delgado J: Risk factors in the critical burn patient. Ann Medit Burns Club 1990, 3:160-165.

48. Clark CJ, Reid WH, Gilmour WH, Campbell D: Mortality probability in victims of fire trauma: revised equation to include inhalation injury. $\mathrm{Br}$ Med J (Clin Res Ed) 1986, 292:1303-1305.

49. Hytonen M, Honkanen R, Asko-Seljavaara S: Incidence of burns requiring hospitalization in Finland in 1980. Ann Chir Gynaecol 1987, 76:218-221.

50. Akerlund E, Fredrik RM, Huss R, Sjöberg F: Burns in Sweden: an analysis of 24,538 cases during the period 1987-2004. Burns 2007, 33:31-36.

51. Bloemsma GC, Dokter J, Boxma H, Oen IM: Mortality and causes of death in a burn centre. Burns 2008, 34:1103-1107.

52. Brusselaers N, Hoste EA, Monstrey S, Colpaert KE, De Waele JJ, Vandewoude $\mathrm{KH}$, Blot SI: Outcome and changes over time in survival following severe burns from 1985 to 2004. Intensive Care Med 2005, 31:1648-1653.

53. Galeiras R, Lorente JA, Pertega S, Vallejo A, Tomicic V, de la Cal MA, Pita S, Cerda E, Esteban A: A model for predicting mortality among critically ill burn victims. Burns 2009, 35:201-209.

54. Brusselaers N, Juhasz I, Erdei I, Monstrey S, Blot S: Evaluation of mortality following severe burns injury in Hungary: external validation of a prediction model developed on Belgian burn data. Burns 2009, 35:1009-1014

55. Zoch G, Schemper M, Kyral E, Meissl G: Comparison of prognostic indices for burns and assessment of their accuracy. Burns 1992, 18:109-112.

56. Onarheim H, Jensen SA, Rosenberg BE, Guttormsen AB: The epidemiology of patients with burn injuries admitted to Norwegian hospitals in 2007. Burns 2009, 35:1142-1146.

57. Rimdeika R, Kazanavicius M, Kubilius D: Epidemiology of burns in Lithuania during 1991-2004. Medicina (Kaunas) 2008, 44:541-547.

58. Papp A: The first 1000 patients treated in Kuopio University Hospital Burn Unit in Finland. Burns 2009, 35:565-571.

59. Elisdottir R, Ludvigsson P, Einarsson O, Thorgrimsson S, Haraldsson A: Paediatric burns in Iceland: hospital admissions 1982-1995, a population-based study. Burns 1999, 25:149-151.

60. Papp A, Rytkonen T, Koljonen V, Vuola J: Paediatric ICU burns in Finland 1994-2004. Burns 2008, 34:339-344.

61. Dempsey MP, Orr DJ: Are paediatric burns more common in asylum seekers? An analysis of paediatric burn admissions. Burns 2006, 32:242-245.

62. Rawlins JM, Khan AA, Shenton AF, Sharpe DT: Epidemiology and outcome analysis of 208 children with burns attending an emergency department. Pediatr Emerg Care 2007, 23:289-293. 
63. Lindblad BE, Terkelsen CJ: Domestic burns among children. Burns 1990 16:254-256.

64. Chapman JC, Sarhadi NS, Watson AC: Declining incidence of paediatric burns in Scotland: a review of 1114 children with burns treated as inpatients and outpatients in a regional centre. Burns 1994, 20:106-110.

65. Dedovic Z, Brychta P, Koupilova I, Suchanek I: Epidemiology of childhood burns at the Burn Centre in Brno, Czech Republic. Burns 1996, 22:125-129.

66. Cronin KJ, Butler PE, MCHugh M, Edwards G: A 1-year prospective study of burns in an Irish paediatric burns unit. Burns 1996, 22:221-224.

67. Mercier $\mathrm{C}$, Blond $\mathrm{MH}$ : Epidemiological survey of childhood burn injuries in France. Burns 1996, 22:29-34.

68. Eadie PA, Williams R, Dickson WA: Thirty-five years of paediatric scalds: are lessons being learned? Br J Plast Surg 1995, 48:103-105.

69. Vipulendran V, Lawrence JC, Sunderland R: Ethnic differences in incidence of severe burns and scalds to children in Birmingham. BMJ 1989, 298:1493-1494.

70. Zeitlin R, Somppi E, Jarnberg J: Paediatric burns in central Finland between the 1960s and the 1980s. Burns 1993, 19:418-422.

71. Bradshaw C, Hawkins J, Leach M, Robins J, Vallance K, Verboom K: A study of childhood scalds. Burns Ind Therm Inj 1988, 14:21-24.

72. Klasen $\mathrm{HJ}$, ten Duis HJ: Changing patterns in the causes of scalds in young Dutch children. Burns Ind Therm Inj 1986, 12:563-566.

73. Lyngdorf P: Epidemiology of scalds in small children. Burns Ind Therm Inj $1986,12: 250-253$.

74. Benito J, Navarro A, Montahana J, Mena A, De La Cruz LI, Mirabet V: A study of burns in children. Ann Medit Burns Club 1991, 4:79-83.

75. Celko AM, Grivna M, Danova J, Barss P: Severe childhood burns in the Czech Republic: risk factors and prevention. Bull World Health Organ 2009, 87:374-381.

76. Kripner J, Broz L, Konigova R, Bouska I: Mortality in pediatric burns in the Prague Burns Centre (1994-1997). Acta Chir Plast 1998, 40:79-82.

77. Zamecnikova I, Stetinsky J, Tymonova J, Kadlcik M: Burn injury in children. Acta Chir Plast 2005, 47:13-15.

78. Enescu D, Davidescu I, Enescu M: Paediatric burns in Bucharest, Romania; 4327 cases over a 5-year period. Burns 1994, 20:154-156.

79. Bortolani A, Barisoni D: Burns in the elderly: epidemiology and mortality: analysis of 53 cases. Ann Burns Fire Disast 1997, 10:197-199.

80. Cutillas M, Sesay M, Perro G, Bourdarias B, Castede JC, Sanchez R: Epidemiology of elderly patients' burns in the South West of France. Burns 1998, 24:134-138.

81. Khadim MF, Rashid A, Fogarty B, Khan K: Mortality estimates in the elderly burn patients: the Northern Ireland experience. Burns 2009, 35:107-113.

82. Koupil J, Brychta P, Rihova H, Kincova S: Special features of burn injuries in elderly patients. Acta Chir Plast 2001, 43:57-60.

83. Lumenta DB, Hautier A, Desouches J, Gouvernet J, Giorgi R, Manelli JC, Magalon G: Mortality and morbidity among elderly people with burns: evaluation of data on admission. Burns 2008, 34:965-974.

84. Rao K, Ali SN, Moiemen NS: Aetiology and outcome of burns in the elderly. Burns 2006, 32:802-805.

85. Sarhadi NS, Kincaid R, McGregor JC, Watson JD: Burns in the elderly in the south east of Scotland: review of 176 patients treated in the Bangour Burns Unit (1982-91) and burn inpatients in the region (1975-91). Burns 1995, 21:91-95.

86. Tejerina C, Reig A, Codina J, Safont J, Mirabet V: Burns in patients over 60 years old: epidemiology and mortality. Burns 1992, 18:149-152.

87. Zoch G, Meissl G, Bayer S, Kyral E: Reduction of the mortality rate in aged burn patients. Burns 1992, 18:153-156.

88. Klosova $\mathrm{H}$, Tymonova J, Adamkova M: Burn injury in senior citizens over 75 years of age. Acta Chir Plast 2005, 47:21-23.

89. Herd BM, Herd AN, Tanner NS: Burns to the elderly: a reappraisal. Br J Plast Surg 1987, 40:278-282.

90. WHO: Suicide Prevention in Europe: the WHO European monitoring survey on national suicide prevention programmes and strategies. Brussels: WHO 2002.

91. Brusselaers $\mathrm{N}$, Monstrey $\mathrm{S}$, Blot $\mathrm{S}$ : The FLAMES score accurately predicts mortality risk in burn patients (Gomez M et al., 2008). J Trauma 2009, 67:415.

92. Wasiak J, Spinks A, Ashby K, Clapperton A, Cleland H, Gabbe B: The epidemiology of burn injuries in an Australian setting, 2000-2006. Burns 2009, 35:1124-1132.
93. Pegg SP: Burn epidemiology in the Brisbane and Queensland area. Burns 2005, 31(Suppl 1):S27-31.

94. Han TH, Kim JH, Yang MS, Han KW, Han SH, Jung JA, Lee JW, Jang YC, Burd A, Oh SJ: A retrospective analysis of 19,157 burns patients: 18-year experience from Hallym Burn Center in Seoul, Korea. Burns 2005, 31:465-470.

95. Ryan CM, Schoenfeld DA, Thorpe WP, Sheridan RL, Cassem EH, Tompkins RG: Objective estimates of the probability of death from burn injuries. N Engl J Med 1998, 338:362-366.

doi:10.1186/cc9300

Cite this article as: Brusselaers et al: Severe burn injury in europe: a systematic review of the incidence, etiology, morbidity, and mortality. Critical Care 2010 14:R188.

\section{Submit your next manuscript to BioMed Central and take full advantage of:}

- Convenient online submission

- Thorough peer review

- No space constraints or color figure charges

- Immediate publication on acceptance

- Inclusion in PubMed, CAS, Scopus and Google Scholar

- Research which is freely available for redistribution

Submit your manuscript at www.biomedcentral.com/submit
Ciomed Central 